\title{
Manifestações de futuros professores que ensinam matemática em ações que envolvem grandezas e medidas
}

\author{
Anemari Roesler Luersen Vieira Lopes ${ }^{1}$ \\ Simone Pozebon ${ }^{2}$ \\ Maiara Luisa Klein ${ }^{3}$
}

\section{RESUMO}

Tendo como objeto de reflexões a formação inicial, este artigo propõe-se a discutir sobre manifestações de futuros professores diante de uma situação desencadeadora de aprendizagem relativa a grandezas e medidas, especificamente sobre volume. No espaço do Clube de Matemática da Universidade Federal de Santa Maria (UFSM), acadêmicos participaram de estudos e ações relacionadas ao ensino e aprendizagem de matemática, pautados na Teoria Histórico-Cultural, especialmente na Teoria da Atividade e na Atividade Orientadora de Ensino, originando os dados empíricos deste trabalho. A análise apresentou indicativos de que futuros professores, quando colocados diante de situações desencadeadoras de aprendizagem, nem sempre superam o apelo ao material sensorial como única forma de busca de solução, o que caracteriza o pensamento empírico. Como decorrência dos resultados, aponta-se, na formação inicial, a relevância do acesso a espaços que possibilitem reflexões que permitam ir para além dos conhecimentos considerados como aprofundamentos da futura área de ensino.

\footnotetext{
1 Pós-Doutora em Educação. Universidade Federal de Santa Maria, Santa Maria, Rio Grande do Sul, Brasil. https://orcid.org/0000-0002-4636-9618. anemari.lopes@gmail.com.

2 Doutora em Educação. Universidade Federal do Rio Grande do Sul, Porto Alegre, Rio Grande do Sul, Brasil. https://orcid.org/0000-0002-3872-5117. spozebon@gmail.com.

3 Mestranda em Educação. Universidade Federal de Santa Maria, Santa Maria, Rio Grande do Sul, Brasil. https://orcid.org/0000-0001-5867-5375. maiara103@hotmail.com.
} 
PALAVRAS-CHAVE: Formação Inicial de Professores. Grandezas e Medidas. Clube de Matemática.

Expressions of future teachers who teach mathematics in actions involving actions and measures

\begin{abstract}
With the object of initial formation reflections, this article proposes to discuss expressions of future teachers facing a learning-triggering situation relating to quantities and measures, focusing on volume. At the Federal University of Santa Maria Mathematics Club, students participated in studies and actions related to teaching and learning of mathematics, based on the Historical-Cultural Theory and especially on Activity Theory and Teaching Guiding Activity, providing the empirical data of this study. The analysis showed indications that future teachers, when faced with situations that trigger learning, do not always overcome the appeal to sensory material as the only way to search for a solution, which characterizes empirical thinking. As a consequence of the results, it is pointed out, in the initial formation the relevance of access to spaces that allow discussions and reflections reaching beyond the knowledge considered as further development of the future teaching area.
\end{abstract}

KEYWORDS: Initial Teacher Formation. Quantities and Measures. Mathematics Club.

\title{
Manifestaciones de futuros profesores que enseñan matemáticas en acciones que involucran grandezas y medidas
}

\section{RESUMEN}

Teniendo como objeto de reflexiones la formación inicial, este artículo se propone discutir sobre manifestaciones de futuros profesores delante de una situación desencadenadora de aprendizaje relativa a grandezas y medidas, específicamente sobre volumen. En el espacio del Club de Matemáticas, de la Universidad Federal de Santa Maria (UFSM), académicos participaron de estudios y acciones relacionadas a la enseñanza y el aprendizaje de matemáticas, pautados en la Teoría Histórico-Cultural, especialmente en la Teoría de la Actividad y en la Actividad Orientadora de Enseñanza, originando los datos empíricos de 
este trabajo. El análisis presentó indicativos de que futuros profesores, cuando puestos delante de situaciones desencadenadoras de aprendizaje, ni siempre superan el llamado al material sensorial como único modo de búsqueda de solución, lo que caracteriza el pensamiento empírico. En virtud de los resultados, se señala, en la formación inicial, la relevancia del acceso a espacios que posibiliten discusiones y reflexiones que permitan ir más allá de los conocimientos considerados como profundizaciones de la futura área de enseñanza.

PALABRAS CLAVE: Formación Inicial de Profesores. Grandezas y Medidas. Club de Matemáticas.

\section{Introdução}

Considerar que a matemática é produto histórico e cultural e que, a partir dela, é possível criar novas interações no âmbito social, permite compreendê-la para além de um componente curricular, reduzido a números, fórmulas e memorização. Aquiesce a possibilidade de vislumbrar seu significado como instrumento a ser utilizado na resolução de problemas socialmente estabelecidos. E são as necessidades de resolver esses problemas, derivados de situações vivenciadas pela humanidade, que geram motivos para o ser humano transformar o mundo objetal, levando a novos conhecimentos. Esse movimento assegura que a humanidade se desenvolva, pois é a partir da apropriação dos conhecimentos que os sujeitos vão desenvolvendo suas máximas capacidades intelectuais, constituindo-se como gênero humano. Desse modo, temos a matemática como instrumento fundamental no processo de humanização, pois ela, como tantos outros, proporciona criar novas condições de o sujeito se humanizar, por meio de sua atividade.

Leontiev (1988), em sua Teoria da Atividade, nos ajuda a compreender a atividade humana como um processo psicológico que, partindo de uma necessidade, leva o sujeito a se apropriar dos produtos 
historicamente produzidos. Assim, não é qualquer ação que fará com que ele desenvolva novas aptidões psíquicas, estas precisam ser oriundas de uma necessidade particular que lhe permitirá colocar-se em movimento, orientado por um motivo, traçando ações que lhe exijam conhecimentos.

Conduzindo essa discussão para a educação, Moura (1996) propõe a Atividade Orientadora de Ensino (AOE), entendida como um embasamento teórico referendado na Teoria Histórico-Cultural e, mais especificamente, na Teoria da Atividade, de Leontiev, e metodológico, trazendo elementos que possibilitam organizar o ensino de matemática, compreendida como elemento cultural, derivado de necessidades humanas e, como tal, de direito de aquisição de todos.

Pensar o processo de apropriação do conhecimento almejando o desenvolvimento, requer objetivar o conhecimento teórico, que é aquele que promove as inter-relações entre os aspectos internos e externos do objeto, a totalidade e a aparência, o original e o derivado (DAVIDOV, 1982). Isso implica que os sujeitos - quer estudantes da Educação Básica quer ainda professores em formação inicial - sejam colocados em situações que promovam a necessidade de mobilizar conhecimentos que, utilizados como ferramentas de resolução de problemas, podem levar à aquisição de novas capacidades intelectuais.

Nessa perspectiva, entendemos que o futuro professor, como sujeito cuja atividade principal será o ensino, vai se constituindo a partir da apropriação de conhecimentos que lhe favorecem ocupar esse novo papel social (não mais de aluno, mas sim de professor). Daí decorre a relevância de que, no curso de licenciatura, haja oportunidades de apropriação do objeto de conhecimento com o qual lidará - como a matemática - de modo a permitir-lhe desvelar a sua essência por meio de suas particularidades e seus detalhes internos, bem como do próprio processo de constituição do objeto. E isso advém de uma aprendizagem pautada no pensamento teórico (DAVIDOV,1982). 
É no contexto de aprender a ser professor que ensinará matemática que este artigo está inserido, com o propósito de discutir sobre manifestações de futuros professores diante de uma Situação Desencadeadora de Aprendizagem (SDA) relativa a grandezas e medidas, mais especificamente sobre volume. Sendo assim, discorremos sobre ações desenvolvidas no projeto de extensão Clube de Matemática(CluMat) da Universidade Federal de Santa Maria (UFSM), âmago da presente investigação, com acadêmicas ${ }^{4}$ dos cursos de Licenciatura em Educação Especial, Matemática e Pedagogia.

O recorte da pesquisa que ora apresentamos se refere especificamente ao estudo desenvolvido entre as integrantes do projeto desencadeado a partir de uma situação voltada ao conceito de volume, que tinha o intuito de fomentar discussões concernentes ao seu ensino e aprendizagem, tendo em vista que é um conteúdo trabalhado nos anos iniciais e finais do Ensino Fundamental.

Assim sendo, apresentaremos brevemente alguns apontamentos teóricos, bem como os caminhos perpassados pela pesquisa. Conseguinte, discorreremos sobre as manifestações das futuras professoras diante da situação proposta. Por fim, traremos considerações sobre o estudo realizado.

\section{Alguns apontamentos teóricos}

A matemática, como um componente curricular, na maioria das vezes, é compreendida como um rol de regras e fórmulas a serem memorizadas para o momento da avaliação e, após isso, esquecidas. Todavia, compreendendo o conhecimento sistematizado - tal como a matemática como produto cultural e histórico, ela suplanta essa visão reducionista e passa a assumir seu significado social de instrumento de interação, atuação e transformação do espaço em que o sujeito vive.

Sabendo que na escola acontecem diferentes interações e que é nela que o conhecimento sistematizado é apresentado para o aluno, podemos

\footnotetext{
${ }^{4}$ Referenciamos as participantes da pesquisa no gênero feminino, pois este espaço se constituía apenas por mulheres.
} 
reconhecê-la como local estabelecido para viabilizar a apropriação de conhecimentos produzidos social e historicamente, como a matemática. Assim,

A educação escolar, entendida como a satisfação de uma necessidade coletiva de incluir novos membros recém-chegados à comunidade, deverá levar à apropriação de conhecimentos que lhes permitirão ser identificados como parte dessa comunidade. (MOURA; SFORNI; LOPES, 2017, p.89)

$\mathrm{Na}$ perspectiva do que os autores nos trazem, a escola é (ou deveria ser) um dos lugares intencionalmente organizados para que o sujeito se aproprie da cultura historicamente elaborada que lhe possibilitará a atuação e a inserção na vida social do grupo ao qual pertence. Os conhecimentos, bem como sua organização na forma de componentes curriculares, são resultados de um processo que faz parte da história humana e, por isso, sua apropriação deve servir como instrumento de desenvolvimento das máximas capacidades intelectuais do sujeito.

É no processo humano de apropriação e transformação dos conhecimentos que novos conceitos vão se constituindo, com novas qualidades, como um produto cultural que favorece a interação social.

Así, el conocimiento, puesto como produto cultural a ser aprendido, se torna um instrumento de intervención del sujeito, al apropiar-se , a su modo,de una fomra de intervención em su médio cultural. Se trata de dar significado al qué aprender; no sólo para el sujeto, sino también para toda la institución escolar. Dar significado al aprendizaje de la matemática es dar sentido también a la educación. (MOURA, 2011, p.54)

Dentre tantos conhecimentos que auxiliam na intervenção do sujeito no meio social, temos os matemáticos que, compreendidos como produtos de 
um processo histórico, se compõem como um agente importante para resolver os problemas estabelecidos coletivamente, resultando no aprimoramento da vida humana. Isso justifica a importância da aprendizagem dessa disciplina na escola.

Aprender un languaje matemático es más que aprender códigos y reglas. Es aprender un método de conocer y transmitir lo que se conoce. Es también saber aplicar lo que se conoció em la solución de problemas que les son proprios em la convivencia com otros. Es hacer-se humano. (MOURA, 2011, p.52)

A matemática é muito mais que um conhecimento materializado como componente curricular estático, é uma linguagem produzida como resposta às necessidades humanas e facilita ao sujeito se inserir na vida em comunidade, cujas interações refletirão em novas qualidades em suas ações sociais.

Mas a apropriação da experiência social não é um processo inato. Ela acontece em dois planos, tal como nos ensina Vigotsky (2007, p. 23).

No desenvolvimento cultural, todas as funções entram duas vezes em cena, em dois planos diferentes: primeiro, no Social, logo no plano psicológico; primeiro como uma forma de cooperação entre as pessoas, como uma categoria coletiva e interpsicológica, depois como meios de comportamentos individuais, como uma categoria intrapsicológica.

O movimento das funções psíquicas superiores existe primeiramente no plano social para, então, passar para o plano individual - de cada sujeito - o que nos leva a entender a importância do ensino nesse processo. Para Vigostki (1982, p. 237), "la instrucción se adelanta em lo fundamental al desarrollo", ou seja, são as aprendizagens sociais - em especial as 
adquiridas por meio de um processo intencional de quem ensina - que subsidiarão o desenvolvimento de cada sujeito.

Nessa direção, temos que o ensino é promotor de desenvolvimento, e o professor, ao organizá-lo, precisa levar em consideração as aprendizagens que subsidiarão a aquisição de novas capacidades por seus alunos, o que não é proporcionado por qualquer atividade. Assim, não entendemos atividade como uma simples ação, mas aquela que proporciona o desenvolvimento psíquico,

[...] por atividade, designamos os processos psicologicamente caracterizados por aquilo a que o processo, como um todo, se dirige (seu objeto), coincidindo sempre com o objetivo que estimula o sujeito a executar esta atividade, isto é, o motivo. (LEONTIEV, 1988, p. 68)

No caso da educação escolar, para que o aluno esteja em atividade de modo a promover o desenvolvimento das funções psicológicas superiores, mediante um determinado conhecimento, é preciso que uma necessidade impulsione o motivo, para ele se apropriar de conhecimentos estabelecidos socialmente, propostos pelo professor.

A primeira condição de toda atividade é uma necessidade. Todavia, em si, a necessidade não pode determinar a orientação concreta de uma atividade, pois e apenas no objeto da atividade que ela encontra a sua determinação: deve, por assim dizer, encontrar-se nele. Uma vez que a necessidade encontra a sua determinação no objeto (se "objetiva" nele), o dito objeto torna-se motivo da atividade, aquilo que o estimula. (LEONTIEV, 1978, p. 115)

A atividade do estudante - entendida nesta ótica - parte de uma necessidade que se concretiza no motivo, responsável por dirigir as suas 
ações de estudo, e envolve motivos, desejos, necessidades e emoções. É a atividade que o movimenta rumo à apropriação do conhecimento.

Todavia, há de se considerar dois tipos de conhecimento, o empírico e o teórico, que "correspondem a dois tipos de pensamento, igualmente empírico e teórico, de maneira que o indivíduo pode abordar a realidade de duas maneiras bem distintas" (RUBTSOV, 1996, p.120). Os conhecimentos empíricos são concretizados pela comparação e observação de objetos, criando apenas generalizações a partir da atribuição de juízo, e é resultante da relação direta com a realidade. $O$ autor ressalta que qualquer conhecimento empírico se baseia na observação e reflete apenas as propriedades exteriores dos objetos, apoiando-se inteiramente nas representações concretas.

Já o teórico origina-se de uma transformação dos objetos e reflete as relações entre as suas propriedades e suas ligações internas. E, "tão logo o pensamento reproduz um objeto sob a forma de conhecimento teórico, ele supera as representações sensoriais" (RUBTSOV, 1996, p.129). Assim, o conhecimento teórico passa a se constituir como uma ação mental, na qual

El primero momento le permite al homebre tomar conciencia en el proceso del pensamiento que indendientemente del mismo existe el objeto, dado como premisa de la actividad. Esta premisa comunica al concepto el momento de pasividad, caráter contemplativo y de independencia respecto al contenido objetivo. Y sin embargo, tener noción del objeto dado supone reporducirlo mentalmente, construilo. Esa eperación de construir y transformar el objeto mental equivale al acto de comprenderlo, explicarlo y revelar su esencia. (DAVIDOV, 1982, p.301)

Trazendo essa discussão para a educação escolar, Freitas (2016, p.403-404) explica que 
Para Hedegaard e Chaiklin (2005), o conhecimento teórico pode ser considerado como uma ferramenta para associar os conceitos nucleares de uma matéria ao conhecimento cotidiano, local e pessoal, e esse caráter é que importa ser ressaltado na aprendizagem dos alunos. Estudar e aprender um objeto dessa forma torna o aluno capaz de basear-se em conceitos como uma perspectiva geral para agir considerando a perspectiva do contexto particular, local, e entender o particular e local é como uma concretização do geral.

Mas, como a própria autora alerta, esse não é um processo que ocorre de forma mecânica e automática. Faz-se pertinente organizar adequadamente o ensino para possibilitar aos estudantes a apropriação dos objetos de conhecimentos e seus respectivos conceitos teóricos, visando ao desenvolvimento de suas máximas capacidades intelectuais. Nessa direção, Rubtsov (1996, p.131) indica que

[...] a adoção de uma atitude teórica diante da realidade e o emprego de meios apropriados para adquirir os conhecimentos teóricos são considerados uma necessidade específica e um motivo suficiente para o aprendizado.

Daí a relevância de propor aos estudantes problemas de aprendizagem confrontando-os com uma situação "cuja solução em todas as variantes concretas pede uma aplicação do método teórico generalista" (RUBTSOV, 1996, p.131) e, que lhes permitam criar formas de ação geral de resolvê-los.

Tendo em vista a apropriação do conhecimento teórico, entendido como a síntese da produção da cultura a partir das necessidades humanas, destacamos a Atividade Orientadora de Ensino (AOE) como embasamento teórico e metodológico, que nos auxilia organizar o ensino de matemática a partir de alguns princípios orientadores, de tal forma que contemple o movimento perpassado pela humanidade ao produzir o conhecimento. A 
AOE considera a atividade como precursora do desenvolvimento do sujeito, pois busca aproximar o estudante da necessidade humana de criar o conceito por meio do que denomina Situação Desencadeadora de Aprendizagem.

Nas ações de ensino e de aprendizagem o problema desencadeador aparece sob determinadas condições singulares, isto é, materializado sob a forma de uma situação desencadeadora de aprendizagem. Esta, busca criar os meios ou instrumentos para que os sujeits se engagem no processo de resolução daquele problema que sintetiza o conceito que se quer ensinar. (NASCIMENTO, ARAUJO, 2019, p,681, grifos no original)

É por meio da Situação Desencadeadora de Aprendizagem que o professor possibilitará aos alunos a apropriação do produto social sintetizado no conhecimento. $\mathrm{Na}$ busca de modos gerais para resolver as problematizações coletivamente o sujeito poderá aprender um novo conhecimento.

Cabe aqui ressaltar que entendemos que, na formação inicial de professores, esse processo também pode contribuir para a aquisição de novos conhecimentos necessários para a docência. No processo inicial de formação, os futuros professores atribuem novos sentidos tanto ao exercício do trabalho pedagógico, quanto ao objeto de seu ensino, pois, mesmo que já tenham vivências relacionadas a isso, foram frequentadores do ambiente escolar por muito tempo e precisam ir para além do olhar de aluno.

Autores como Pimenta (1999, p.120) já vêm nos chamando a atenção há algum tempo para o fato de que, quando os alunos chegam ao curso de licenciatura, trazem consigo conhecimentos sobre o que é ser professor, por meio de suas experiências de conviver com diferentes professores na sua vida escolar. Tais experiências lhes autorizam a dizer, por exemplo, "quais foram os bons professores, quais eram bons em conteúdo, mas não em didática, isto é, não sabiam ensinar”. Daí poder dizer que 
o desafio, então, posto aos cursos de formação inicial é o de colaborar no processo de passagem dos alunos de seu ver o professor como aluno ao seu ver-se como professor. Isto é, de construir a sua identidade de professor. Para o que os saberes da experiência não bastam. (PIMENTA, 1999, p. 20)

É neste desafio apresentado pela autora há mais de duas décadas, mas ainda a ser enfrentado, amparado nos pressupostos elencados neste item, que se coloca nossa pesquisa cujos caminhos serão apresentados a seguir.

\section{Caminhos da pesquisa}

A formação inicial constitui-se como um espaço em que estudantes precisam se apropriar de conhecimentos que lhes permitam assumir um novo papel social: o de professor. Esses conhecimentos resultarão em possibilidades de contribuir com sua futura prática pedagógica, com sua necessidade de organizar o ensino quando estiverem diante de seus alunos.

Dessa premissa decorre a relevância de que nos cursos de licenciatura os sujeitos tenham oportunidades de se apropriar de diferentes conhecimentos, o que nos leva ao espaço onde foi desenvolvida a pesquisa: o Clube de Matemática. O CluMat da UFSM iniciou suas ações em 2009 e, desde então, possui como enfoque a interação entre a universidade e a escola de Educação Básica, propiciando continuamente o movimento de estudo, organização, desenvolvimento e avaliação de atividades de ensino desencadeadas em escolas públicas de Santa Maria.

As participantes da pesquisa foram 11 estudantes dos cursos de licenciatura, sendo 2 da Educação Especial, 4 da Matemática e 5 da Pedagogia. Durante o ano em que a investigação foi desenvolvida, essas acadêmicas participaram do desenvolvimento de ações envolvendo diferentes conteúdos matemáticos. Contudo, neste artigo apresentaremos 
um recorte do estudo realizado, direcionando nosso olhar para as que envolveram os conhecimentos de grandezas e medidas, mais especificamente sobre volume. As ações foram as seguintes: leitura individual; discussão coletiva de textos; e desenvolvimento e discussão coletiva de situações desencadeadoras de aprendizagem.

Ao proporcionar essas ações focadas em conhecimentos matemáticos, a intenção foi atentar para o movimento voltado ao ensino, entendendo que discutir sobre conhecimentos considerados básicos - os quais já deveriam ser apropriados na Educação Básica - permite a atribuição de novos sentidos a eles, uma vez que o seu olhar não será mais de aluno, mas de um sujeito constituindo-se professor. Embora tenham sido desenvolvidas ações posteriores com alunos da Educação Básica, estas não serão aqui abordadas, uma vez que nosso foco nesse momento se centra nos futuros professores.

Todos os momentos foram gravados em áudio e vídeo com a devida autorização dos participantes e seguindo as orientações do Comitê de Ética e Pesquisa de nossa instituição (CEP/UFSM). Posteriormente, por compreender que "frases escritas ou faladas, gestos e ações que constituem cenas podem revelar interdependência entre os elementos de uma ação formadora" (MOURA, 2004, p. 276), transcrevemos as falas e essas, originaram as cenas, selecionadas para a análise.

Discorreremos no próximo subitem duas cenas sobre situações desenvolvidas, tendo em vista a contemplação de nosso objetivo neste artigo, qual seja, discutir sobre manifestações de futuros professores diante de uma Situação Desencadeadora de Aprendizagem relativa a grandezas e medidas, mais especificamente sobre volume.

\section{A Situação Desencadeadora de Aprendizagem como mote de discussão}

Compreendemos o conhecimento, tal qual explicitado anteriormente, como premissa para a interação do sujeito com o meio social tendo em vista 
a apropriação da cultura humana. Assim, desde muito cedo, adquirimos diversos conhecimentos espontâneos que nos permitem interagir nos grupos sociais em que vivemos, como a família, os amigos e a escola. Todavia, para a criação de novas formas de interação e até mesmo transformar as estabelecidas, é necessário que os conhecimentos se ampliem e ultrapassem a empiria. Isso exige que ao sujeito sejam oferecidas possibilidades e experiências nas quais utilizarão o conhecimento tecido pela humanidade, avançando do patamar empírico para alcançar o teórico, uma vez que este não está inserido de maneira direta no âmbito social.

É com essa ideia que temos nos apoiado na proposta de Moura (1996) da Atividade Orientadora de Ensino, por meio de Situações Desencadeadoras de Aprendizagem, visando à apropriação de conceitos. Tal como propõe o autor, estas devem ser problematizadas baseando-se no movimento do conceito perpassado pela humanidade, objetivando que o sujeito se coloque na necessidade de sua utilização como ferramenta da solução da situação proposta. Portanto, ao intencionarmos discutir sobre o conceito de volume com os futuros professores, entendemos que não poderíamos partir de suas sínteses materializadas nas fórmulas matemáticas, mas sim, de uma SDA proposta por uma situação emergente do cotidiano.

As 11 participantes foram divididas em dois grupos e foi-lhes apresentado um problema relativo ao transporte de Material Dourado. O critério para a formação dos mesmos foi a participação de, pelo menos, uma componente de cada curso em cada grupo, com o intuito de eliminar possíveis distinções derivadas da formação inicial. Corriqueiramente, para desenvolver as ações do CluMat nas escolas, os acadêmicos usam algumas peças dos conjuntos disponíveis do Laboratório de Matemática Escolar (LEME) da universidade, mas não levam a caixa completa ${ }^{5}$ (pela dificuldade

\footnotetext{
${ }^{5}$ O Material Dourado é baseado em um dos materiais idealizados pela médica e educadora Maria Montessori para trabalhar com aritmética, em especial o Sistema de Numeração Decimal. Os conjuntos (organizados em caixas de madeira) que compõem o acervo do LEME são formados por peças de madeira ou EVA: cubo de $10 \mathrm{~cm}$ de aresta, representando o milhar; placas de $10 \mathrm{~cm} \times 10 \mathrm{~cm} \times 1 \mathrm{~cm}$, representando as centenas; barras de $10 \mathrm{~cm} \times 1 \mathrm{~cm} \times 1 \mathrm{~cm}$, representando as dezenas; e cubinhos de $1 \mathrm{~cm} \times 1 \mathrm{~cm}$, que representam as unidades.
} 
de transporte) e precisam carregá-las em outro recipiente (caixinha de papelão, pote,...). Por diversas vezes já havia sido cogitada a construção de caixinhas de papelão especificamente para este transporte, o que originou o seguinte problema desencadeador de aprendizagem: "Como podemos descobrir qual a menor caixinha possível que permite levar o material, de forma a utilizar a menor quantidade de papelão?”. Cada grupo recebeu o material que normalmente era levado à escola: um cubo (milhar), dez placas (centenas), dez barras (dezenas) e dez cubinhos (unidades) do Material Dourado. Podendo manipular este material, teriam que discutir sobre como descobrir qual a menor caixa de papelão que poderia ser montada para conter esse material.

Com o intuito de discutir as manifestações iniciais, trazemos na Cenas 01 e 02 a resolução primeira encaminhada pelos grupos. Ressaltamos que, após essas discussões, aconteceram a apresentação e a discussão geral entre os dois grupos, buscando uma síntese coletiva, mas, por motivo de espaço deste artigo e por não ser objetivo neste momento, não será aqui apresentada.

Quadro 01: Cena 1- Resolução da Situação Desencadeadora de Aprendizagem pelo Grupo 01

Descrição da Cena 1:

O diálogo a seguir refere-se à discussão da solução pelo Grupo 01.

1. Rose: Nós, na verdade, iniciamos olhando os tamanhos e pensamos um pouco, mas não nos detemos aos cálculos. Aí todas as possibilidades que tentamos...[mostrando os diversos modos que encontraram de "empilhar" o material]

2. Orientadora: Então, [...] vocês foram fazendo as hipóteses a partir do material?

3. Rose: $E$, e todas nós enxergávamos, na verdade, a mesma coisa [mostrando o modo que todas acharam o melhor]. Pensamos como as crianças fariam no processo delas. Aí chegamos numa caixa que caberiam dois mil e duzentos, no caso sobra lugar para nove barrinhas. [o total do volume das barrinhas era 2110]

4. Orientadora: Aí vocês fizeram uma caixinha que cabe dois mil e duzentos [unidades de cubinhos]?

5. Rose: Isso.

6. Orientadora: Vocês chegaram aos dois mil e duzentos depois, ou primeiro partiram dele para construir a caixinha?

7. Rose: Depois. Primeiro fomos montando as medidas como achamos que precisava ser.

8. Orientadora: Juntando os cubinhos. Que medida vocês encontraram?

9. Rose: 10,11 e 20 [arestas do paralelepípedo].

[...]

Fonte: Acervo do Clube de Matemática 
Com essa cena, que apresenta a resolução do problema pelo Grupo 1, queremos chamar a atenção para uma manifestação: o apelo à experiência sensorial. O diálogo indica que a solução foi encontrada somente manuseando o material a fim de chegar nas hipóteses para representar o tamanho do recipiente que seria construído. Ressalta-se que chegaram à resposta bem antes do outro grupo.

O manuseio de material sensorial como única forma de chegar a uma resposta caracteriza o pensamento empírico, uma vez que inicia pelo exame das relações e atributos externos do objeto, permitindo a sua apreensão de modo imediato. A resolução de um problema baseada somente no processo de manusear e visualizar o material sensorial permite aos sujeitos se apropriarem de conhecimentos, contudo, eles se situam no âmbito empírico. Davidov (1988) lembra que o princípio do caráter visual e concreto (objetal) apoia os conhecimentos empíricos e que, embora as ações mentais promovidas por esse tipo de conhecimento possam ser importantes, devem ser apenas o início do processo rumo aos conhecimentos teóricos. O objetivo da organização do ensino bem como da inserção dos sujeitos no âmbito escolar é desenvolver o pensamento teórico.

El contenido del pensamiento teórico es la existencia mediatizada, reflejada, essencial. El pensamineto teórico es el processo de idealización de uno de los aspectos de la actividad objetal-prática, la reprodúcion, en ella, de las formas universales de las cosas. Tal reprodúcion tiene lugar em la actividad laboral de las personas como peculiar experimento objetal-sensorial. Luego este experimento adquire cada vez más um carácter cognoscitivo, permitiendo a las personas passar, com el tiempo, a los experimentos realizados mentalmente. (DAVIDOV, 1988, p. 125)

É partindo dos conhecimentos teóricos que o homem se apropria da cultura humana mais elaborada que, utilizada mentalmente, dispensa o apelo ao objeto sensorial e passa a desenvolver novas generalizações. 
Vejamos, a seguir, a resolução do Grupo 02.

\section{Quadro 02: Cena 2- Resolução da Situação Desencadeadora de Aprendizagem pelo Grupo 02}

Descrição da Cena 02: Esta cena aconteceu concomitante à cena 1, todavia apresenta a conclusão que o Grupo 2 chegou referente à SDA proposta.

Organizando o material, as acadêmicas iniciaram colocando as placas, as barras e os cubinnhos sobre o cubo grande e perceberam algumas dificuldades.

1. Luna: O problema será os cubinhos.

2. Lara: Os cubinhos são dez. E agora?

3. Manuella: $E$ se colocarmos [barras] um pouco ali [comprimento da base] e um pouco aqui [barras na lateral] e esses [cubinhos] aqui [aresta do cubo].

4. Márcia: Tipo uma fileira aqui [aresta do cubo]?

$[\ldots]$

5. Sophia: Precisa ser necessariamente [bases e faces] um quadrado?

6. Luna: Eu acho que não, pode ser um retângulo também. Pode ser uma forma retangular que ocupe menos espaço, podendo analisar ele de pé ou deitado, de comprimento, porém, precisa ocupar o menor espaço.

7. Lara: Eu acho que podemos continuar com o tamanho do cubo.

8. Luna: Mas falta um ou sobra um. Eu acho que vamos mexendo ele para um lado [montar o restante dos materiais ao lado do cubo], mas não precisa necessariamente... vamos pensar em cálculos: temos que ter uma base, uma precisa

$[\ldots]$ ser par e a outra precisa ser impar.

9. Manuella: Precisa ser em formato de cubo, pois aqui [comprimento da base] vai dar muito se multiplicarmos os comprimentos.

$[\ldots]$

10. Luna: Então a forma que ocupamos não tem a ver se falta ou não espaço.

11. Sophia: Precisa completar, ficar "certinho"?

12. Pesquisadora: Não necessariamente. Precisa ter o menor espaço.

$[\ldots]$

13. Luna: Então é medir o volume. Por que ele não vai ocupar só a área plana [base], ele vai ocupar todo o espaço.

14. Sophia: Então temos que calcular o volume que ele ocupa?

$[\ldots]$

15. Luna: Como todas as unidades completam o cubinho, podemos usar o cubinho como unidade de medida, tipo uma unidade, e calcular o volume. A barra que é uma figura retangular é o comprimento, a largura e a altura.

16. Alice: $A$ ordem não altera o produto. Indiferente do espaço que ele ocupar, o volume será o mesmo por causa da multiplicação das três dimensões.

$[\ldots]$

17. Luna: Qual é mesmo o volume das peças?

18. Sophia: Dois mil cento e dez.

19. Luna: Se fizermos uma forma que for cúbica, o volume do cubo é cúbica. Então, eu preciso descobrir se há uma raiz cúbica para esse valor, para ver se dá exato. Se for, precisa ser um número que termina em zero.

20. Manuella: Temos que ver se está certo. Mas eu acho que não vai dar exato, porque aquela hora não deu o cubo todo, por isso as medidas não estão sendo exatas.

21. Luna: Então, em formato de cubo não vai ser, vai ser em formato com base retangular, porque quando resolvemos achar a raiz do cubo não deu uma raiz exata, então quer dizer que as medidas não seriam exatas. 
22. Luna: Pensamos no seguinte: poderíamos ter tentado por hipóteses, mas pensando um pouco que o homem criou uma fórmula para calcular o volume e, sabendo que já conhecia o volume do espaço, tentamos utilizar a fórmula do volume. Como temos figuras retangulares, pensamos no volume do cubo para ver se conseguiríamos montar um cubo. Quando calculamos vimos que dava quebrado, não exato.

[...]

23. Orientadora: Como vocês chegaram no dois mil cento e dez?

24. Luna: calculando o volume de cada peça e somando elas.

$[\ldots]$

25. Luna: Partindo do valor dois mil cento e dez, fizemos o básico: como ele termina em zero, ele é divisível por dez. A partir disso encontramos duas medidas e tentamos pegar a outra medida com hipóteses, tentando dividir. Ai partimos do pressuposto de tentar diminuir o volume para ver se sobrariam peças, só que não deu certo. Só que quando aumentamos o volume, vimos que, conforme aumentava dez unidades, sobrava uma barrinha. A partir disso fizemos a conta $e$ aumentamos para noventa esse volume e vimos que sobrou nove barrinhas. Em outra hipótese, aumentamos cinquenta e sobrou cinco barrinhas. Mas depois vimos que poderíamos ter tentando com cubinhos. Assim, no final chegamos a conclusão que o máximo que sobrou foi cinco barrinhas, encontrando as dimensões dez, doze e dezoito, chegando um volume de dois mil cento e sessenta.

Fonte: Acervo do Clube de Matemática

Essa cena apresenta a resolução da SDA pelo Grupo 2, desde a exploração do material até a conclusão final, trazendo a maneira como foi realizada e a solução encontrada para a caixa, que foi construída posteriormente. Conseguinte as falas, gostaríamos de discutir três manifestações relacionados às ações desenvolvidas: a necessidade de utilizar os cálculos - a fórmula como síntese que supera a experiência empírica sensorial; o compartilhamento como propulsor do conhecimento; a possibilidade de aproximação ao conceito teórico.

O conceito matemático pode ser considerado como objeto da mente humana com um conjunto de significados, que vai além das diferentes experiências sociais e favorece a compreensão e a apropriação de conhecimentos. Conforme coloca Moura (2011, p. 55), é

[...] un objeto concreto producido para ser útil a un sujeto que quiere comprender un certo fenómeno, sea él físico o social. El concepto matemático es un objeto de la mente humana, producido al producir objetos y al reflexionar sobre formas naturales que puedan tener algún significado para la vida. El contenido 
matemático, como objeto social, encierra un conjunto de significados que deberán ser compartidos.

No caso de nossas participantes, o diálogo perpassa diversos conceitos que amparam as hipóteses criadas sobre como poderiam resolver o que estava sendo proposto, que não foram elencados explicitamente na SDA, porém, foram utilizados, mesmo que empiricamente.

Nas falas 1, 2 e 3 da Cena 2, as acadêmicas refletem acerca do material utilizado (Material Dourado), o qual já era de conhecimento delas, podendo, assim, partindo de suas medidas, verificar que não conseguiriam encontrar um valor exato, pois, como Luna declara (fala 1) os cubinhos representavam "o problema“. Então, quando Sophia questiona se a base e as arestas do recipiente precisariam ser em forma de quadrado (fala 9), são levantadas duas hipóteses, uma por Luna (fala 10), afirmando que poderiam ser um formato retangular, e outra por Lara, (fala 11) a qual não se mostra muito convencida com o formato retangular, preferindo continuar com a ideia do cubo (com base em forma quadrada). Essa situação evidencia que, embora nosso objetivo fosse trabalhar com o conceito de volume, a SDA exigiu outros conhecimentos (quadrado, retângulo, base, aresta). Isso nos remete a Vigotsky (2003, p. 72), ao explicar que

[...] a formação dos conceitos é seguida por sua transferência para outros objetos: o sujeito é induzido a utilizar os novos termos ao falar sobre outros objetos que não os blocos experimentais, e a definir o seu significado de uma forma generalizada.

Ao ser apresentada a SDA, as acadêmicas se confrontaram com um determinado problema, no qual, a cada nova hipótese, novos termos surgiam como parte necessária à resolução daquela situação, determinando um movimento para além do objeto inicial. Todavia, a SDA apresentada partiu de uma situação cotidiana, e os sujeitos tinham aproximação com o problema e também com o material. Embasados em Davidov (1982, p. 297), 
podemos dizer que, enquanto puramente experiência sensorial, a solução da problematização pode não ter ultrapassado os conhecimentos empíricos, advindos dos reflexos e da utilização direta com aquele material, podendo, assim, não ter chegado à generalização teórica.

Posteriormente as discussões do Grupo 2 sobre estas hipóteses, avançaram para a necessidade de utilização de cálculos para verificar qual seria o menor tamanho possível do recipiente que construiriam, como afirma Luna (fala 12). E esta é a primeira manifestação para que chamamos a atenção, pois, no desenvolvimento das ações, visualizamos a necessidade de superação da experiência sensorial por meio da utilização do cálculo para encontrar um resultado mais preciso, mais exato. $\mathrm{Na}$ fala 25 , a participante Luna explica a maneira que encontraram para saber se o recipiente poderia ou não ser um cubo, afirmando, após ter realizado o cálculo, que o recipiente não tem forma do cubo, pois a raiz cúbica de 2.110 não é exata. A referência à raiz cúbica adveio da fórmula do volume do cubo $\left(\mathrm{V}=\mathrm{a}^{3}\right)$.

Precisar construir a caixinha para enchê-la com o material já tinha conduzido as estudantes a relacionarem com o "espaço" que o material ocupava. Mas, em recorrência aos cálculos, é possível identificar a relação que fazem com o volume. Observamos um movimento em que, inicialmente, conseguiram achar uma maneira de verificar as possibilidades de solucionar o problema com o material, mas este já não era mais suficiente. Assim, a utilização do cálculo como maneira de resolver o problema proposto, tendo em vista que as hipóteses sensoriais (de ir montando o material) não estavam suprindo as suas necessidades de fazê-lo na forma mais exata, apontam para um caminho semelhante ao movimento humano perpassado para criar maneiras mais rápidas e eficazes de resolver problemas sociais, trazendo indicativos da apropriação das fórmulas matemáticas como sínteses que superam a experiência empírica sensorial.

Retomamos novamente Moura (2011), quando alega que num primeiro momento temos a imitação como condutor da apropriação direta do conhecimento, na qual, após fazer uso da palavra que faz juz ao que 
aprendeu, o sujeito estará desenvolvendo novas maneiras de fazer uso dela, podendo, portanto, se apropriar do conhecimento empírico de uma maneira direta com o meio social e, assim, evoluir para o conhecimento teórico. Sabendo que o conhecimento empírico é diferente do conhecimento teórico e que é somente pelo segundo que o indivíduo tem as possibilidades de desenvolver suas máximas capacidades intelectuais, há de se considerar que a organização do ensino deve permitir ao sujeito aprendente ir além daquilo que a experiência sensorial lhe proporciona, ir além do conhecimento empírico. No nosso caso, os sujeitos já tinham conhecimentos, mas estes estavam empiricamente relacionados ao material.

Vigotsky(2007) explica que a aprendizagem ocorre do nível social para o individual, com as relações intrapsíquicas (do sujeito) constituindo-se a partir das relações interpsíquicas (entre os sujeitos). Dessa forma, é pelas relações que estabelecem que o sujeito se apropria dos conhecimentos socialmente estabelecidos, sendo estes, num primeiro momento, de cunho social para então passar para o individual.

Ao pensar no desenvolvimento dos sujeitos, interagindo entre eles, criando hipóteses e suposições, evidenciamos possibilidades de apropriação de conhecimentos sistematizados universalmente por meio do movimento humano lógico e histórico. $\mathrm{Na}$ Cena 2, percebemos indícios de manifestação de um processo compartilhado, com diálogos que fazem os outros sujeitos repensarem suas hipóteses, criando condições novas para chegar na resposta, como nas falas 9, 10, 11 e 12, em que as acadêmicas refletem acerca da forma geométrica do recipiente.

Destacamos, ainda, uma terceira manifestação, retomando a referência das acadêmicas à palavra "espaço", especialmente nas falas 7, 10 e 14. Nessas falas podemos identificar que, mesmo antes de terem se referido explicitamente ao volume que o material ocupa, já há elementos referentes a esta grandeza que, como traz Bendick (1965, p.22), é “o espaço ocupado por qualquer coisa”. Entendemos que isso não pode ser visto como elemento único de apropriação de conhecimento teórico, uma vez que o 
conceito de volume vai além do que o autor aponta. Contudo, consideramos como resultado do movimento das discussões anteriores do grupo - um indicativo de que as ações desenvolvidas iam na direção de aproximação ao conceito de volume.

\section{Conclusão}

Compreendemos, a partir do que nos coloca Davidov $(1982,1988)$ e Rubtsov (1996), que o conhecimento teórico é o conteúdo da atividade do sujeito que aprende e vai promover o desenvolvimento do pensamento teórico, uma vez que tem predomínio no que se refere à aprendizagem e permite o conhecimento do objeto em sua totalidade, envolvendo os aspectos universal e singular (DAVIDOV, 1982). Mas o desenvolvimento do pensamento teórico não acontece de forma espontânea, exige a intencionalidade da organização do ensino o que, na compreensão de Rubtsov (1996, p.131), implica em colocar o sujeito diante de um problema de aprendizagem que lhe permita a "aquisição das formas de ação gerais e, com elas, a aquisição de conhecimento teórico". Dessa maneira, espera-se que o sujeito em situação de aprendizagem se coloque em atividade, na perspectiva de Leontiev $(1978,1988)$.

A partir desses pressupostos basilares trouxemos à tona manifestações da resolução de uma Situação Desencadeadora de Aprendizagem resolvida por futuras professoras que ensinarão matemática, divididas em dois grupos que apresentaram encaminhamentos distintos.

O primeiro grupo encontrou uma solução para o problema proposto apoiando-se exclusivamente na manipulação do material que tinha a seu dispor. Embora a resposta encontrada tenha possibilitado a apropriação de um conhecimento (que permitiria, no caso, a construção da caixa), nesse momento não superou o empírico, uma vez que este sustenta-se inteiramente nas representações sensoriais, refletindo apenas as propriedades exteriores dos objetos, como sustenta Davidov $(1988,1982)$. 
Podemos entender que o problema proposto se configura para esses futuros professores - pelo menos no momeno inicial - como um problema prático (RUBTSOV, 1996), já que lhes permitiu chegar somente na solução imediata. A necessidade do grupo era encontrar a solução para o tamanho da caixinha e não um modo geral de construir caixinhas o que, claramente, demonstra que não se concretizou como atividade na perspectiva de Leontiev $(1978,1988)$. Isso nos impõe a reflexão sobre quais possibilidades limitaram a aprendizagem desses sujeitos, sendo que alguns indicativos podem ser encontrados na análise da resolução do Grupo 02.

O segundo grupo buscou um caminho diferente, orientado por uma discussão coletiva entre seus componentes, levando-os a um possível modo geral de resolver o problema, materializado na fórmula de obtenção do volume da caixa, entendido como suficiente para o "espaço" a ser ocupado pelo material. Isso pode ser indicativo de que para elas se configurou como um problema de aprendizagem, já que a fórmula pode ser entendida como um modelo, transformado em uma base "que constitui a orientação comum para completar as ações concretas relativas a uma classe de problemas" (RUBTSOV, 1996, p.133).

Melhor dizendo, a fórmula por elas encontrada não serve somente para o problema da caixa que precisavam produzir, mas para calcular o volume de qualquer paralelepípedo, aproximando-se de uma generalização. Possivelmente as componentes do outro grupo também tivessem conhecimento da fórmula do paralelepípedo, contudo o apelo único ao aspecto sensorial não lhes viabilizou, naquele momento, superar o conhecimento empírico, possivelmente arraigado no modelo que vivenciaram na experiência escolar.

Não estamos afirmando que o Grupo 2 chegou a generalizações teóricas, mas é possível identificar as diferenças entre as soluções dos dois grupos. O primeiro está muito próximo do que normalmente se pode observar na Educação Básica, derivado da ênfase da experiência cotidiana 
empírica dos escolares que, embora consideramos de extrema relevância, em especial nos primeiros anos de escolarização, precisa ser superada.

Para Davydov, o pensamento empírico sustenta uma concepção didática e de organização do ensino em que, equivocadamente, "empírico" significa sensorial, palpável, concreto e teórico significa abstrato, verbal, geral. Nessa concepção didática, o ensino se configura como transmissão de conhecimento e não como um processo de investigação da sua origem e desenvolvimento na forma de conceito.(FREITAS, 2016, p.397, grifos do autor)

$\mathrm{O}$ que aqui apresentamos se trata de um recorte de um processo mais amplo e foi sucedido de um momento posterior de busca de uma síntese coletiva (conforme encaminhamentos da AOE), com o intuito de oportunizar a todas as participantes a aproximação aos conhecimentos teóricos relativos a grandezas e medidas, mais especificamente volume. Tal momento aqui não foi apresentado, pois nossa intenção foi discutir as manifestações iniciais dos futuros professores diante de uma SDA.

Como decorrência dos resultados, apontamos a relevância da inserção dos futuros professores em espaços em que tenham a possibilidade de discutir e refletir, que lhe permitam ir para além dos conhecimentos tidos como aprofundamentos de sua futura área de ensino, dado que foi possível perceber que, mesmo estando em um curso superior, parte delas se apoia unicamente em experiências empíricas, sem domínio teórico de conhecimentos que poderíamos considerar como básicos, já que fazem parte da organização curricular da Educação Básica. Isso porque, caso isso não aconteça, a consequência será a perpetuação do modelo vigente, uma vez que, quando professores, a organização do ensino se pautará nos seus conhecimentos, ou seja, dificilmente alcançará o desenvolvimento do pensamento teórico. 


\section{Referências}

BENDICK, J. Pesos e medidas. São Paulo: Fundo de Cultura, 1965.

DAVIDOV, V. Tipos de generalización en la enseñanza. Havana: Pueblo y Educación, 1982.

DAVIDOV, V. La esneñanza escolar y el desarrollo psiquico. Tradução de Marta Shuare. Moscú: Progresso, 1988.

FREITAS, R. M. M, Formação de conceitos na aprendizagem escolar e atividade de estudo como forma básica para a organização do ensino. Educativa, Goiânia, v. 19, n. 2, p. 388-418, maio/ago. 2016. Disponível em < http://seer.pucgoias.edu.br/index.php/educativa/article/view/5392/2955>

LEONTIEV, A. N. O homem e a cultura. In: LEONTIEV, A. N. O desenvolvimento do psiquismo. São Paulo: Editora Moraes Ltda. 1978.

LEONTIEV, A. N. Uma contribuição à teoria do desenvolvimento da psique infantil. In: VIGOTSKII, L.S.; LURIA, A.R.;LEONTIEV, A.N. Linguagem, desenvolvimento e aprendizagem. 5. ed. São Paulo: Ícone, 1988. p.59-83

MOURA, M. O. (coord.) Controle da variação de quantidade. Atividades de ensino. Textos para o ensino de Ciências, n. 7. Oficina Pedagógica de Matemática. São Paulo: USP, 1996.

MOURA, M. O de. Educar con las matemáticas: saber específico y saber pedagógico. Revista Educación y Pedagogía, v..23, n.. 59, p. 47-57, enero/abril, 2011. Disponível em <

https://revistas.udea.edu.co/index.php/revistaeyp/article/view/8691/20796410>

MOURA, M. O.; SFORNI, M. S. F.; LOPES, A. R. L. V.; A objetivação do ensino e o desenvolvimento do modo geral da aprendizagem da atividade. In: MOURA, M. O. (org) Educação escola e a pesquisa na teoria histórico-cultural. São Paulo: Loyola, 2017.

NASCIMENTO, C. P.; ARAUJO, E. S. Contribuições do ensino da Educação Física para o trabalho com o conhecimento teórico na escola. Uberlândia, MG: Ensino Em Re-Vista, v.26, p.677-699, 2019. Disponível em < http://www.seer.ufu.br/index.php/emrevista/article/view/50980/27095>.

PIMENTA, S. G. Formação de professores: identidade e saberes da docência. In: PIMENTA, S. G. (org.). Saberes pedagógicos e atividade docente. São Paulo: Cortez, 1999. p. 15-34.

RUBTSOV, V. A atividade de aprendizagem e os problemas referentes à formação do pensamento teórico dos escolares. In: GARNIER, C. et al. (org.). Após Vygotsky e Piaget: perspectiva social e construtivista. Escola russa e ocidental. Tradução de Eunice Gruman. Porto Alegre: Artes Médicas, 1996. 
VIGOTSKI, L. S. Obras escogidas. Tradução: José Maria Bravo. Moscou: Editorial Pedagógica, 1982. Tomo II.

VYGOTSKY, L. S. Linguagem, desenvolvimento e aprendizagem. 10.ed. São Paulo, SP: Ícone, 2003.

VIGOTSKY, L. S. Interação entre aprendizado e desenvolvimento. In: COLE, M. et al. (org.). A formação social da mente: o desenvolvimento dos processos psicológicos superiores. Tradução de Jose Cippola Neto, Luis Silveira Menna Barreto, Solange Castro Afeche. São Paulo: Martins Fontes, p. 51-58, 2007.

Recebido em abril de 2020.

Aprovado em agosto de 2020. 